\title{
OVERVIEW ABOUT THE INSTRUMENTED NOSE ASSEMBLY DEVELOPMENT FOR THE EXPERT CAPSULE
}

\author{
Thomas Reimer $^{(1)}$, Kornelia Stubicar ${ }^{(1)}$, Georg Koppenwallner ${ }^{(2)}$, Rudolf Müller-Eigner ${ }^{(2)}$, \\ Sebastian Lein $^{(3)}$, Andreas Steinbeck ${ }^{(3)}$ \\ ${ }^{(1)}$ DLR, Institute of Structures and Design, Pfaffenwaldring 38-40, D-70569 Stuttgart, Germany \\ Email:Thomas.Reimer@dlr.de; Kornelia.Stubicar@dlr.de \\ ${ }^{(2)}$ HST GmbH,Max-Planck-Str.19, D-37191 Katlenburg-Lindau, Germany, \\ Email: G.Koppenwallner@htg-hst.de, r.mueller-eigner@htg-hst.de \\ ${ }^{(3)}$ IRS, Institute of Space Systems Universität Stuttgart, D-70569 Stuttgart, Germany, \\ Email:Lein@IRS.Uni-Stuttgart.de,Steinbeck@IRS.Uni-Stuttgart.de
}

\begin{abstract}
The EXPERT mission aims at collecting precise in-flight data during atmospheric re-entry. For this purpose a vehicle was envisaged that is designed especially for that. Almost twenty payloads are on board of the EXPERT capsule which has the shape of a cone with a blunt nose. Four non-moveable flaps are located at the end of the capsule. The nose of the vehicle is made from a ceramic matrix (CMC) composite material. In the nose four exciting experiments are situated. Payload 1 is a Flush Air Data System that measures the pressure and the heat flux in five positions on the nose. Payload 2 collects temperature date on the inside of the ceramic nose at six locations via pyrometric measurements. Payload 10 is a spectrometer that investigates the chemical properties of the boundary layer around the nose via an optical window in the nose. Palyoad 11 is an experiment that deals with the catalycity of materials in the region of the interface of the nose to the adjacent metallic Thermal Protection System (TPS) of the capsule. This paper describes the development of the Instrumented Nose Assembly of the EXPERT capsule, referred to as the NAP, from the design concepts over the analysis and the tests up the flight hardware assembly.
\end{abstract}

\section{MISSION AND DERIVED LOADS}

The NAP is a sub-system of the EXPERT vehicle [1], consisting of the CMC nose and embedded payloads to measure temperature, heat flux and spectroscopic data. EXPERT will be launched on a sub-orbital trajectory with a peak velocity of $5 \mathrm{~km} / \mathrm{s}$. The maximum altitude will be approximately $120 \mathrm{~km}$. The downrange total traveled distance will be $1595 \mathrm{~km}$, with $523 \mathrm{~km}$ after entry interface at $100 \mathrm{~km}$ altitude.

During re-entry the peak heat flux will reach up to $1.5 \mathrm{MW} / \mathrm{m}^{2}$ in the stagnation area assuming a partial catalytic behaviour of the Ceramic Matrix Composite (CMC) material of the nose. Since EXPERT is a ballistic vehicle with a relatively high ballistic coefficient the aerodynamic pressure in the stagnation area reaches a value of up to $3 \mathrm{bar}$, the deceleration peak load factor is $15 \mathrm{~g}$. The aerothermal environment for the EXPERT vehicle during re-entry is typical for a ballistic flight 
from low earth orbit with a relatively small capsule. The ballistic factor is for most of the time during the peak load phase slightly below $1000 \mathrm{~kg} / \mathrm{m}^{2}$. The aerothermodynamic environment was look at more closely in [2].

The trajectory in terms of altitude versus Mach number is plotted in Fig. 1, the time-related heat flux and dynamic pressure are shown in Fig.2.

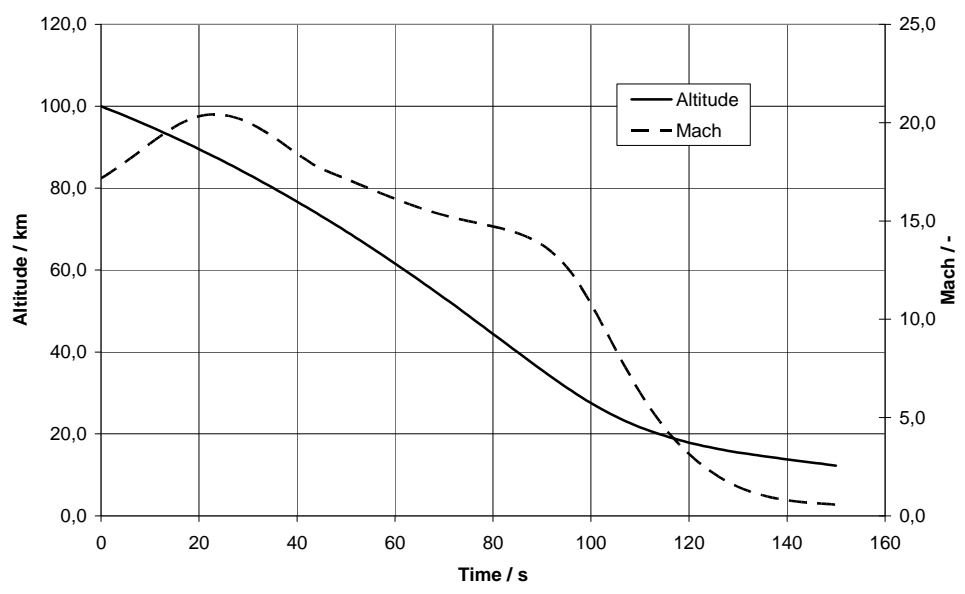

Figure 1: Altitude and Mach number over time.

From these figures it becomes clear that the mission is very demanding for the thermal protection system of the capsule. The peak DKR heat flux is in the range of $1.8 \mathrm{MW} / \mathrm{m}^{2}$ with dynamic pressure at a level of $150 \mathrm{kPa}(1.5 \mathrm{~atm})$.

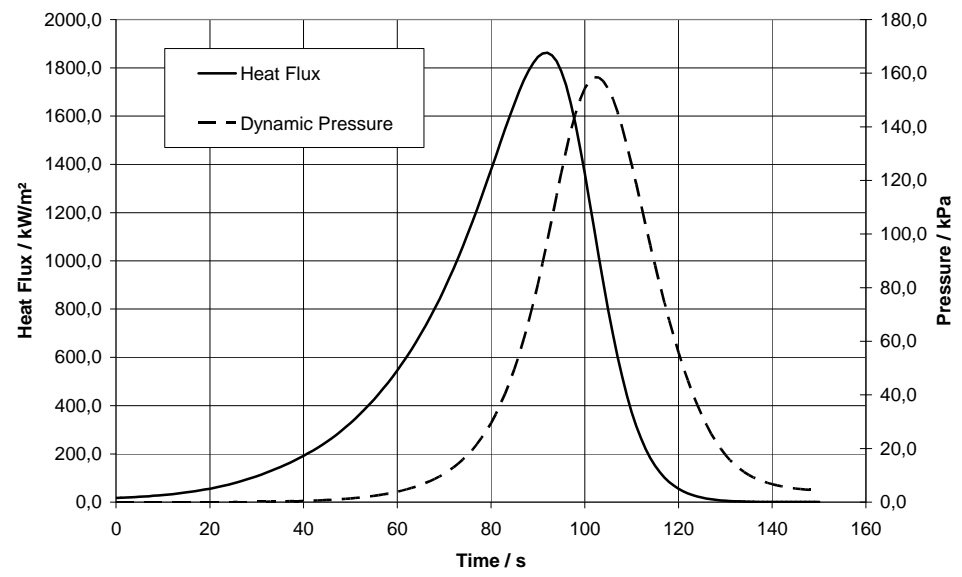

Figure 2: Heat flux and dynamci pressrue over time.

From the equation that relates heat flux to the equilibrium surface temperature, when there is no heat transport into the material, it can be seen that the surface temperatures will be in the range of $2200^{\circ} \mathrm{C}$ assuming an emissivity of 0.85 .

These high temperature levels pose a challenge to the TPS. A choice would be the selection of an ablator as the TPS material in that heat load range, however, an essential issue in the design of the 
TPS in the stagnation region was the requirement to avoid a contamination of the flow around the vehicle as much as possible. Therefore, an ablative material could not be selected. In addition, the interface conditions to the adjacent metallic TPS are very important and have to be very clear [3]. In order to fulfil that requirement the material selection for the nose of the capsule was the ceramic matrix composite (CMC) $\mathrm{C} / \mathrm{C}$-SiC produced from carbon fibres embedded in a silicon carbide matrix. The material shows a good erosion resistance still at these very high temperatures.

Mechanical loads are a critical issue for the system design. They have to be considered during two phases of the mission. First, there is the launch of the vehicle with associated loads that are dominated by vibration and shock loads. Then afer a phase of free flight when the vehicle enters the atmosphere, deceleration loads due to the aerodynamic drag have to be sustained.

The vibration and shock loads during launch are quite severe when compared to other missions due to the launcher that is used. It is the Russian military system R-29 that is converted for the scientific mission.

A numerical analysis of the vibration loads at the capsule interface to the launcher was carried out by Thales-Alenia in Italy. From these calculations the loads in different locations of the capsule were extracted and used for designing the sub-systems. The spectral loads were translated into quasi-static acceleration load cases that are more easily to be analyzed via finite element methods. For the nose assembly the following load cases for the launch were identified at the nose to capsule interface.

Table 1: Vibration load cases.

\begin{tabular}{|c|c|c|c|}
\hline NOSE & \multicolumn{3}{|c|}{ Minimum Frequency $200 \mathrm{~Hz}$} \\
\hline Load Set 1 & Axial [g] & Lateral $[\mathrm{g}]$ & \\
\hline Load Set 2 & $+/-27$ & $+/-18$ & All axes simultaneously \\
\hline Load Set 3 & $+/-36,5$ & $+/-36,5$ & All axes simultaneously \\
\hline Load Set 4 & $-27 /+62$ & $+/-26$ & All axes simultaneously \\
\hline Load Set 5 & $-42 /+66$ & $+/-28$ & All axes simultaneously \\
\hline Load Set 6 & $-22 /+47$ & $+/-9$ & All axes simultaneously \\
\hline
\end{tabular}

The shock loads are generated by the firing of explosive bolts during the staging of the launcher. Accelerations in the range of $1000 \mathrm{~g}$ at a frequency of $1000 \mathrm{~Hz}$ are present for very short times in the nose assembly. The issue will be discussed later in the testing paragraph.

\section{NOSE ASSEMBLY DESIGN}

The mechanical design approach had to consider two goals. First, the nose is exposed to very high temperatures during the re-entry phase. This leads to an expansion of the nose structure in the range of $1 \mathrm{~mm}$ in diameter, even when it is considered that the CMC material shows very low levels of themal expansion. These deformations have to be handled and balanced against the cold structure that will not expand at all.

Second, the mechanical loads in terms of accelerations and pressure are very high due to the rough environment. So the design has to deal with two conflicting tendencies. It has to allow for expansion i.e. movement, but on the other hand it has to be very tough and resisting against the vibration, shock and pressure loads. 
A kinematic solution for the expansion mismatch was investigated briefly but not followed. Instead, a design that relies on the elastic deformation of components was preferred. Figure 3 shows the nose next to the cold structure, Figure 4 with assembled load introduction components and Figure 5 shows the individual load introduction parts. An important issue was that metallic fasteners should be used which necessitates a location for the fastener in a low temperature region. That consideration resulted in the introduction of the profiles on the inside of the nose.

The advantages of the design are that it is simple, easy to install and uses a metallic fastener. In addition there are no disturbances on the nose surface due to bolt heads which might create problems with regard to laminar to turbulent transition of the flow.

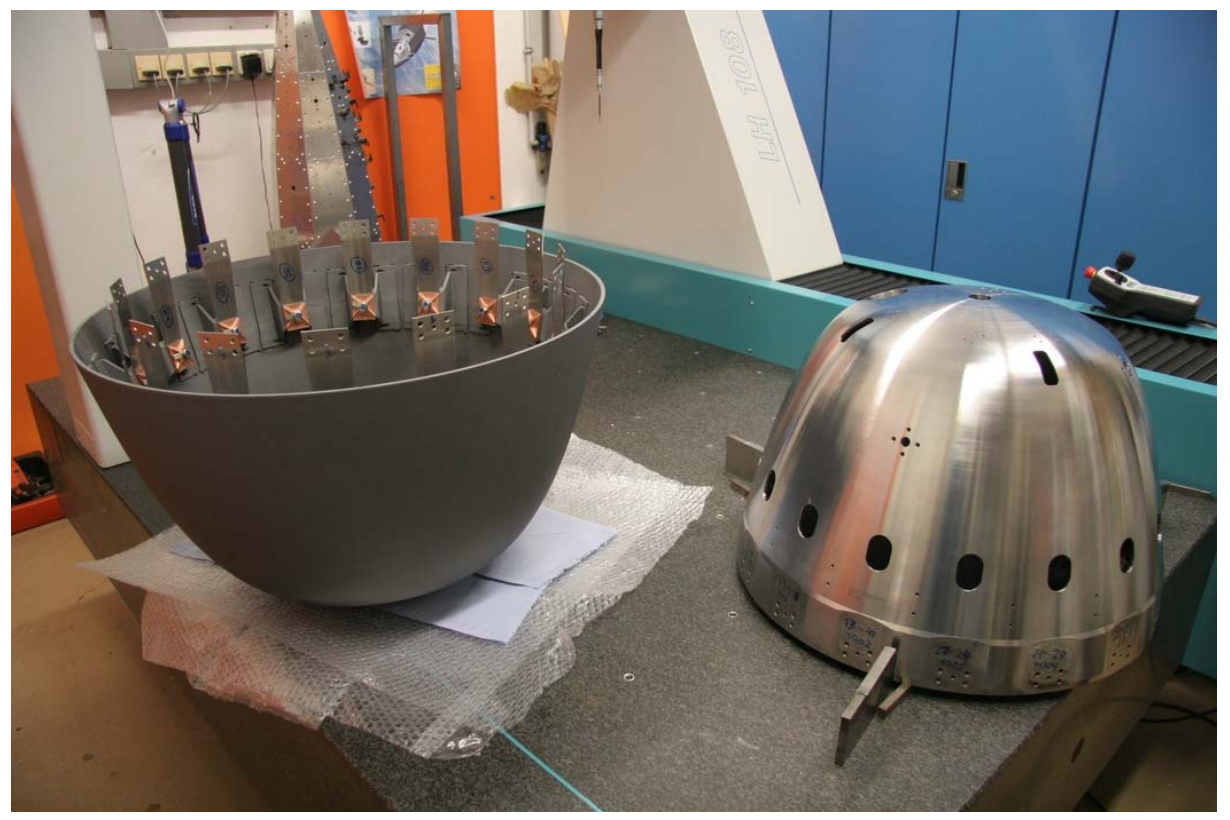

Figure 3: Ceramic nose and steel cold structure

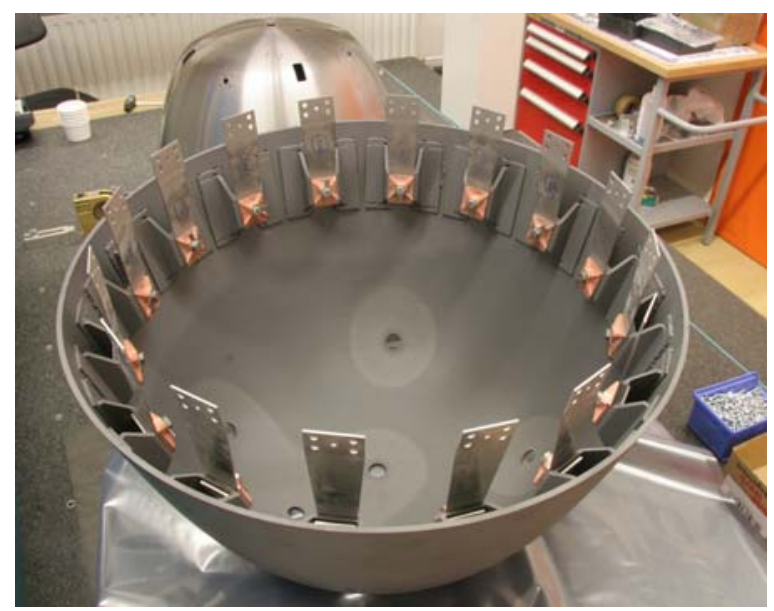

Figure 4: CMC nose with load introductions

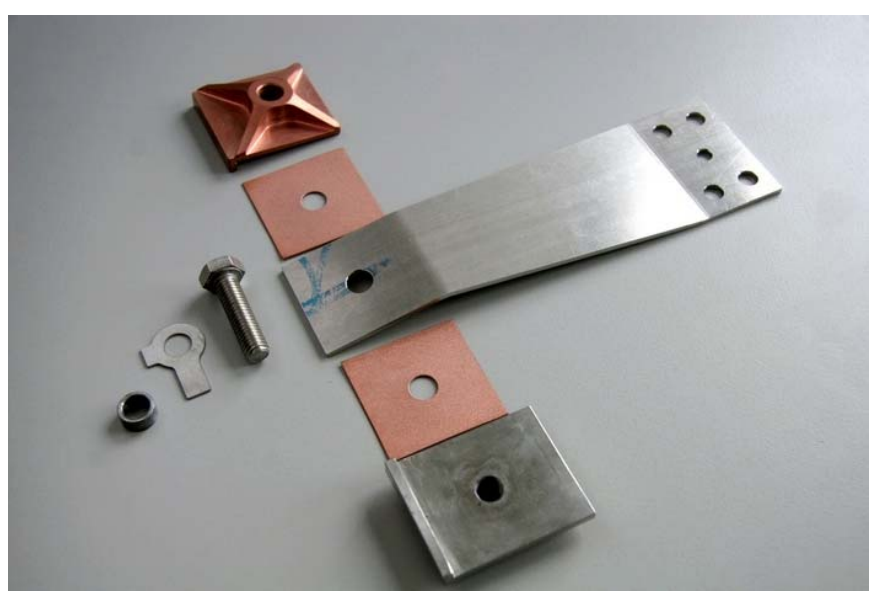

Figure 5: Load introduction components

The design includes a number of metallic strips located around the circumference of the nose (Fig.4). In their longitudinal direction, i.e. in vehicle axial direction, they are stiff, in lateral direction they are flexible to compensate for the thermal expansion of the nose. The design works only because the strips act together. 


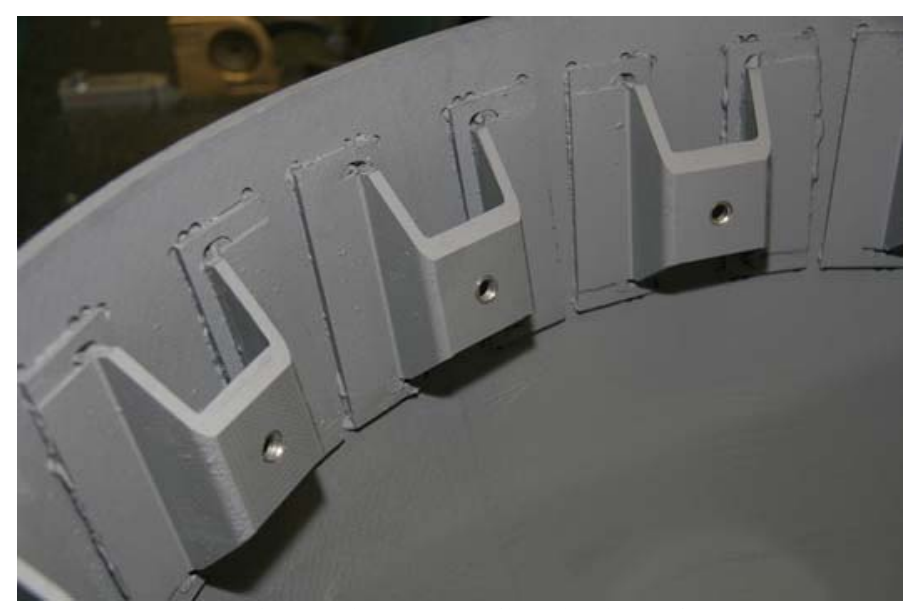

Figure 6: Ceramic hat profiles inside of the nose

At the interface between strips and nose metallic fasteners are used. That was the reason to introduce additional hat profiles on the inside of the CMC nose to move the interface between metallic and ceramic components out of the high temperature region (Fig.6).

\section{NUMERICAL ANALYSIS}

The components were analysed with regard to their mechanical and thermal performance. Mechanical and thermomechanical analyses were carried out to verify the mechanical properties in view of the severe launch and entry loads. The thermal analyses had the aim to establish the thermal environment of the nose and the embedded payloads and to generate the data concerning the overall thermal expansion of the nose (Fig.7). More in detail it was used to verify that certain nose attachment components and the payload items did not exceed their limit use temperature.

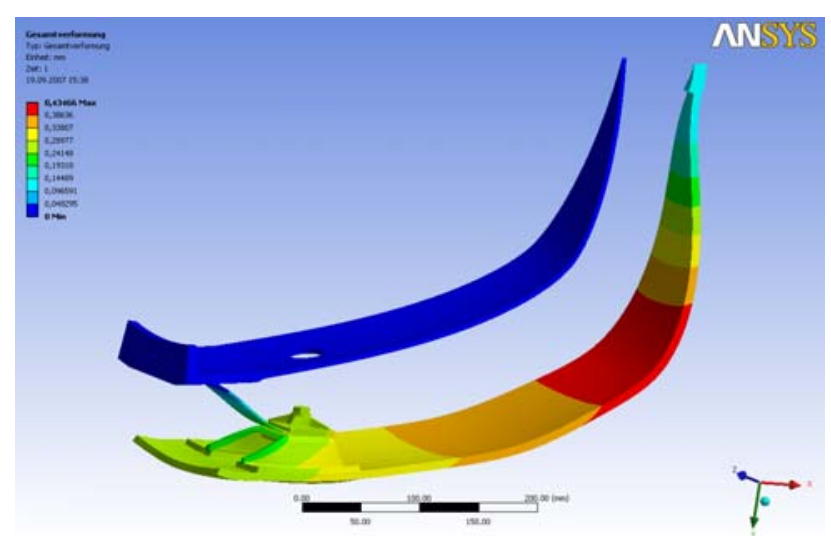

Figure 7: Total deformation of the nose with temperature and pressure applied at time of peak heat load.

The vibration load cases were analysed as static load cases using the quasi-static load levels determined by the vehicle system analysis. In addition an effort was made to analyse the effects of the random vibration load spectrum on the lifetime of the critical components in relation to the launch duration. Since the load introduction is accomplished via thin metallic sheet strips also buckling analyses were carried out. 
It was found that the temperature at the metallic fastener in the connection between nose and cold structure is always low during the mission. Only after landing it rises to roughly $350^{\circ} \mathrm{C}$. The most crucial components are the hat profiles in the nose with regard to mechanical stress. The calculations were done as thermo-mechanical analyses including thermal loads and pressure loads in the re-entry case. For the launch cases, random vibration analysis was done as well as quasi-static analyses that reflect the random vibration loads.

The thermo-mechanical calculations of the re-entry case showed low stresses over the nose in general at below $+30 \mathrm{MPa}$ as shown in Fig. 9. Also in the hat profiles the stress is below $+30 \mathrm{MPa}$ depicted in Fig.8. The material allowables for $\mathrm{C} / \mathrm{C}-\mathrm{SiC}$ are $+80 \mathrm{MPa}$ in tension and $+120 \mathrm{MPa}$ in bending and -200 MPa in compression.

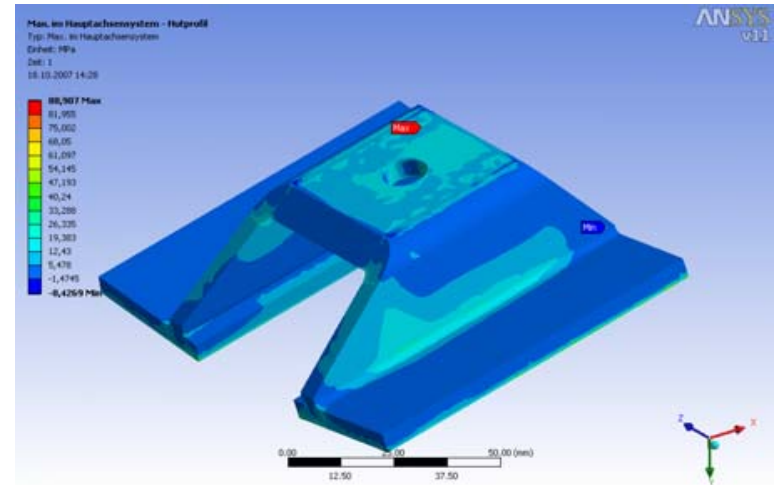

Figure 8: Stress in the hat profile

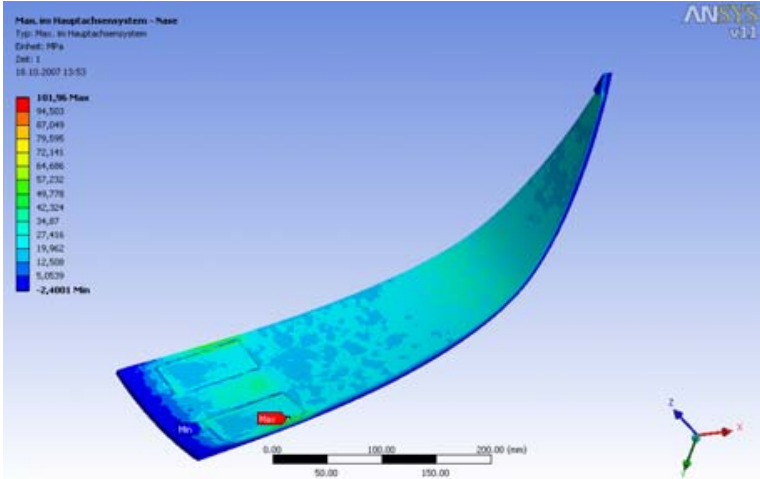

Figure 9: Stress in the nose shell

A detailed investigation of the bond between the hat profile and the nose shell was carried out to verify the bond strength. The goal was to minimise the stress in the bond to very low levels.

The random vibration loads were analysed directly with a random vibration analysis. The calculations showed that the metallic bracket between nose hat profiles and cold structure is in fact the most critical component. After the random vibration analysis with the complete model of the nose assembly, a static analysis was carried out with a submodel of one of the load introductions shown in Fig. 10. The input for the submodel analysis was the displacement result of the random vibration analysis of the complete nose assembly. The submodel included more detailed and realistic contact conditions than the complete model. The highest stresses could be observed around the bolt holes with a peak level of $200 \mathrm{MPa}$ shown in Fig. 11.

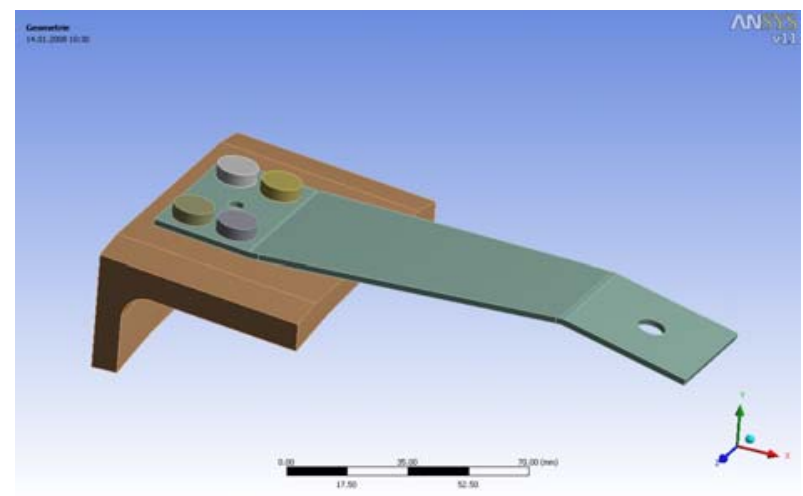

Figure 10: Submodel of the metallic load introduction

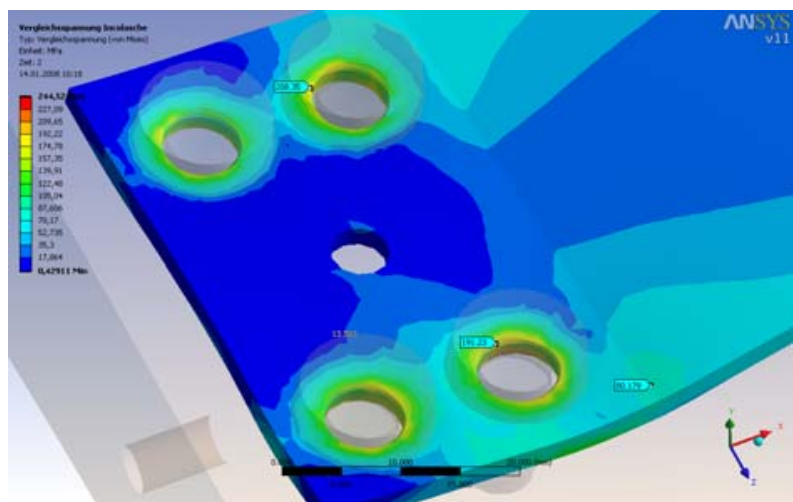

Figure 11: Stress in the metallic bracket 
This is not critical in terms of the static material allowable. However, when it is considered that the launch is a dynamic environment the stress has to be evaluated with regard to that. This means that the lifetime of the component has to be determined under that load. The problem is that there is only very little fatigue data available and there was not enough time to generate the relevant fatigue data before the qualification tests. So an effort was made to estimate the bracket lifetime with the data available and assess the situation. It was found that it is very difficult to arrive at a reliable lifetime prediction since small uncertainties in some parameters used in the lifetime determination have a big impact on the results. The lifetime determination was based on a methodology developed for the use with electronic printed circuit boards (PCB), described by Steinberg [4]. The lifetime of the metallic bracket was found to be long enough to withstand the vibration loads, however, with only a small margin. Ultimately, the vibration tests that were carried out later showed, that all components were well designed.

A buckling analysis was carried out with the load introduction components. The buckling load was determined to be $24.8 \mathrm{kN}$ which results in a margin of safety of 5.5 against buckling of the bracket. So buckling is uncritical. A more detailed discussion of the analysis efforts on the mechanical design is presented in [5].

To illustrate the efforts in the payload analyses, the analysis of the payload 1 sensor head is described. A cross section of the payload 1 sensor head in the nose is shown in Fig. 12. The sensor head of PL01 is called RAFLEX. It is a combined metallic and CMC design because RAFLEX gets into direct contact with the hot nose.

A CMC bolt with countersunk head is inserted into the nose from outside of the nose. It is pulled into the countersunk hole via a spring assembly. The spring has to be protected from excessive temperatures and it is moved away from the nose surface to use transient effects. The distance to the nose is covered by a TZM tube which is a molybdenum alloy. The actual calorimeter is located inside of the CMC bolt. However, it only has mechanical contact to the bolt at its rear end where temperatures stay relatively low. Between calorimeter and bolt, a copper tube creates two circumferential gaps to provide for a radiation shield in order to help keep the calorimeter temperatures acceptable.

The calorimeter features a central orifice where the pressure is obtained and routed to an internal pressure transducer that generates the electrical data signal. The heat flux onto the calorimeter is calculated from the temperature increase in the copper which is measured via two thermocouples.

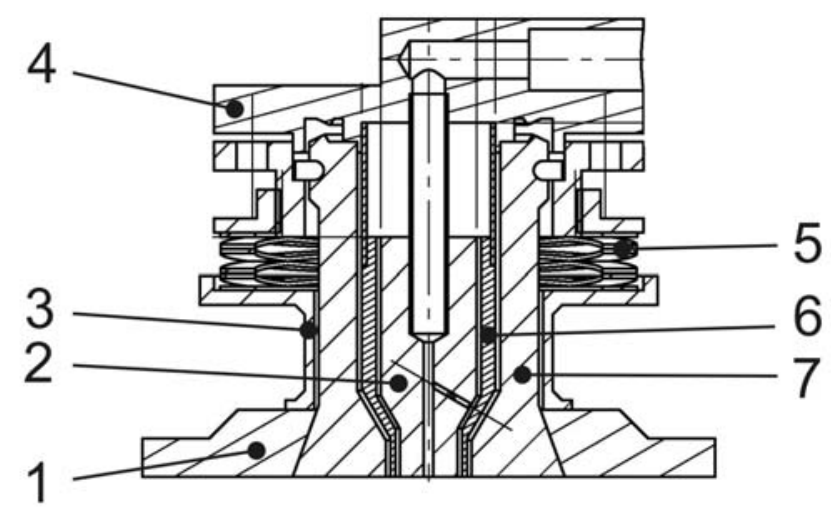

Figure 12: Cross section through the FADS sensor head.

1 CMC Nose 2 Calorimeter 3 TZM tube 4 Steel back plate 5 Spring 6 Radiation shield 7 CMC bolt 
The essential issue in the lay-out was the sizing of the copper calorimeter and to prevent melting. It has to store the thermal energy that it receives during the whole mission since also a heat transfer to the internal structures has to be avoided.

Fig.13 shows the temperature transients that were calculated. The six major components will be discussed here. It can be noted that even though the CMC bolt is in direct contact to the nose, it reaches a maximum temperature of $1800^{\circ} \mathrm{C}$ on the surface of the bolt head which is more than $300^{\circ} \mathrm{C}$ lower than that of the nose. This is a clear indication of the highly transient nature of the mission during which the sensor head assembly never reaches a steady-state but where the CMC bolt is a heat sink in the nose. The TZM tube goes up to $1400^{\circ} \mathrm{C}$ and thus stays below its use limit temperature. The spring is placed at the rear end of the TZM tube and is considerably lower in temperature. The peak value observed there is close to $800^{\circ} \mathrm{C}$. The radiation shield and the steel tube at its back end are very close together and go up to roughly $750^{\circ} \mathrm{C}$.

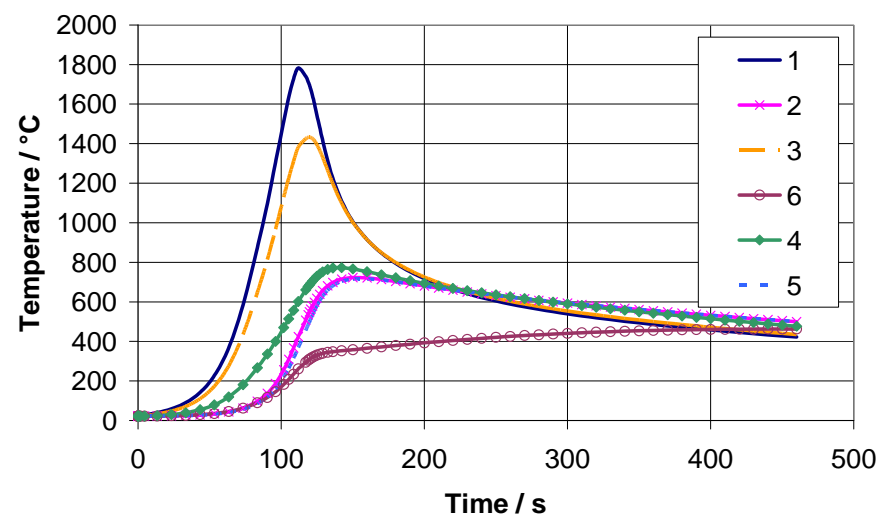

Figure 13: Temperatures in the FADS sensor head obtained via FEA.

1 CMC bolt surface, 2 Radiation shield, 3 TZM tube, 4 Spring, 5 Steel, 6 Calorimeter

The calorimeter itself shows a slightly different behaviour due to the design of the sensor head. Its temperature rise is slower and does not show the distinct peak as the graphs of the other components that were evaluated. At approximately $350^{\circ} \mathrm{C}$ the temperature increase slows down after the time of peak heating in the trajectory was reached but still continues up to $500^{\circ} \mathrm{C}$ when it crosses the graphs of the other components that are already cooling down.

\section{NAP PAYLOADS}

There are four scientific payload subsystems on the NAP.

Payload 1 is the Flush Air Data System (FADS) with the main functional objective of gathering flight data like dynamic pressure, heat flux and vehicle movement. Therefore the pressures and temperatures at five different positions on the TPS nose shall be measured. The free flight dynamic pressure will be derived from the measured stagnation point pressure. The heat flux at each position shall be deduced from the measured temperature rise related to the flight time steps and the material and geometric data of the copper calorimeter. The vehicle movement respectively the angle of attack $(\alpha)$ and the slip angle $(\beta)$ variation over the flight time shall be deduced from the measured pressures of the four probes at the circumference (inclined $45^{\circ}$ ) normalized with the stagnation 
pressure and geometric data of the installation position. A detailed description of the PL1 design and tests is given in [6].

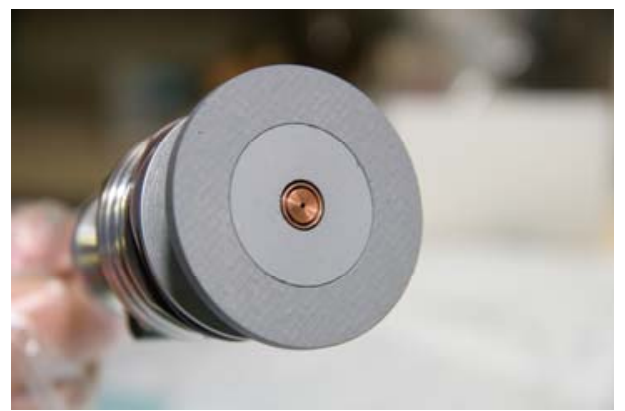

Figure 14: Payload 1 sensor head installed in wind tunnel test article

Payload 2 (PYREX) is a flight-qualified pyrometric entry experiment which measures the TPS rear side temperature distribution. Hence heat fluxes on ceramic TPS can be calculated by solving the inverse heat conduction problem. PYREX is a sensor system for temperature measurements of thermal protection systems with high temporal resolution. To limit the influence of the sensor on the measurement, a contactless pyrometry based principle is used. An additional advantage with respect to temperature measurements by thermocouples is the short response time of the used photodiodes in the PYREX sensor system. The sensor system consists of a six channel electronic unit (SU) and six sensor heads $(\mathrm{SH})$ which are connected via fiber optic cables. The PYREX sensor heads are mounted to the cold structure of the EXPERT nose cap. They consist of a SiC tube and an aligned collimating lens system connected by flanges. The sensor heads are orientated with the axis of the $\mathrm{SiC}$ tube perpendicular to the $\mathrm{C} / \mathrm{C}$-SiC nose cap. The results will allow for the validation of the applied numerical codes used to predict the re-entry heat flux. In addition, thermal effects resulting from the capsule movement, e.g. tumbling during the entry phase, can be identified and used for back calculation of the vehicle movement.

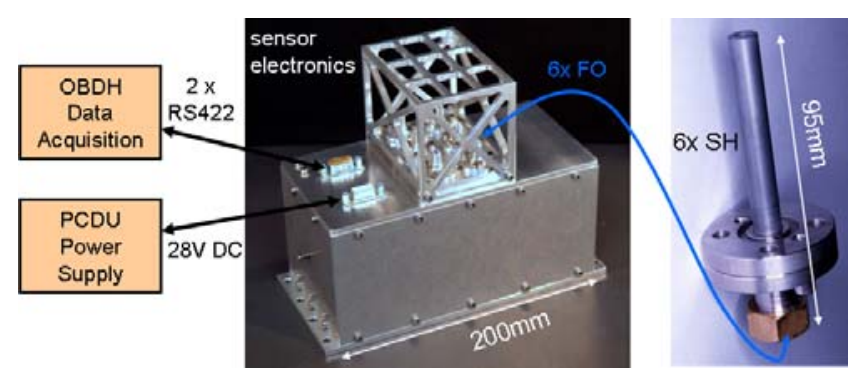

Figure 15: Payload 2 sensor system set-up

Payload 10 (RESPECT) is a sensor system applying optical emission spectroscopy to measure spectrally resolved the radiation onto a TPS surface. By numerically re-building the measurement data using numerical codes such as URANUS and PARADE (Plasma Radiation Database) the plasma composition in the post shock regime can be derived. The sensor system consists of an electronics unit (SU) which connects via fiber optic cables (FO) to the two sensor heads (SH) of the payload. The two spectrometers are connected via fiber optic cables to the two sensor heads of the measurement system. SH1 is located in the stagnation area of the vehicle and hence is integrated into the ceramic $\mathrm{C} / \mathrm{C}$-SiC nose of the EXPERT vehicle. The intensity calibrated sensor system allows for measurement of spectral radiance in the wavelength range of $200 \mathrm{~nm}-850 \mathrm{~nm}$ and therefore the identification of all main species of the air plasma. Beyond the mere identification of the radiating species, the measurement data allows for quantitative analysis of the plasma 
composition by rebuilding the spectrometer signal using numerical simulation. By comparison of measurement data and numerical data, the current status of chemical, physical and radiation modeling implemented in the numerical tools can be validated.

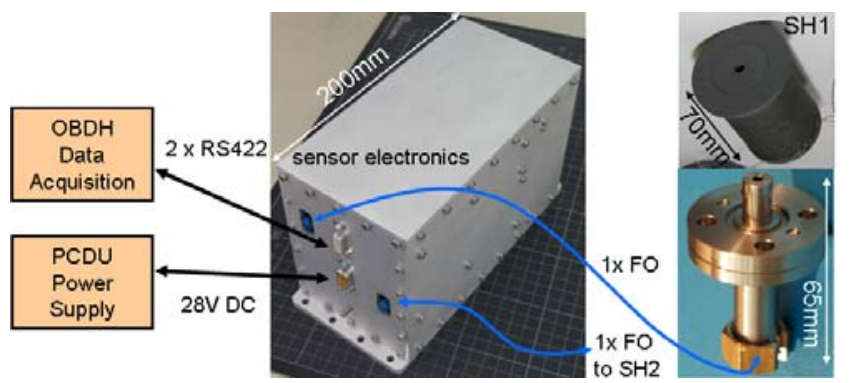

Figure 16: Payload 10 sensor system set-up

Payload 11 includes the junction experiment at the interface between nose and metallic TPS. It consists of thermocouples in the nose and the metallic TPS to measure the temperature rise over the junction from the low catalytic nose to the high catalytic metallic surface. An overview of the payloads on EXPERT not only on the nose can be found in [7].

\section{CMC NOSE MANUFACTURING}

The nose consists of 27 layers of CFRP of different lay-up. The layers 1 to 21 have a different fibre orientation than the layers 22 to 27. After placing the layers into the mould the polymerisation of the CFRP green body was started. After the polymerisation in the autoclave the CFRP nose was tempered. To convert the CFRP part into a porous $\mathrm{C} / \mathrm{C}$ structure, the green body was pyrolysed in a two step pyrolysis process. Hereafter the nose was inspected via computer-tomography. Thereby the nose was rotated around the symmetry axis in increments of $15^{\circ}$.

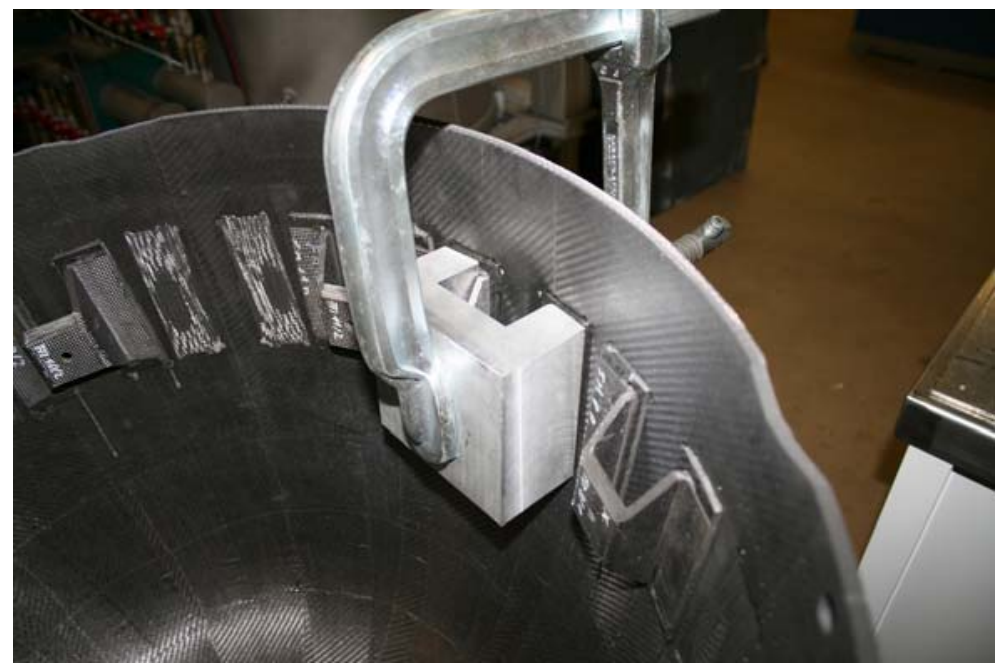

Figure 17: Joining of the hat profiles.

The next step was the calibration with a 3-D measuring machine. Based on the 3D measuring results pockets were machined into the nose. After this the hat profiles for the load introduction were joined into the pockets via an in-situ joining process that is carried out in within the Liquid Silicon Infiltration (LSI) process. The LSI process takes place in vacuum with the addition of silicon granulate. 
Next, the nose was de-siliconized to remove free silicon that wasn't converted into silicon carbide. Subsequent to the siliconizing the nose was again inspected in the computer tomograph to detect any defects in the $\mathrm{C} / \mathrm{C}$-SiC component.

In the following machining process holes were drilled into the nose and it was trimmed in height. After cleaning the nose a CVD-SiC coating was applied on the nose surface. The coating process included 3 coating cycles with a resulting coating thickness of $90-120 \mu \mathrm{m}$. After this the ceramic nose was ready for the NAP assembly.

\section{INSTRUMENTED NOSE ASSEMBLY}

The project was organized in the classic way with a qualification model to be assembled and tested first before going to the production of the flight hardware with subsequent functional checks and acceptance testing. This approach gives room for rehearsing all the processes and procedures that are required. When the qualification campaign is done the lessons learned can be incorporated into the flight units. It proved that this policy was very valuable for the development of the NAP hardware and a significant improvement in the quality of a lot of items could be achieved when transitioning from the qualification to the flight hardware phase.

Since the qualification model and the flight model are essentially the same, the description of the assembly sequence is focused on the flight model only.

In the first step the sensor heads of the FADS of PL1 were pre-integrated in the nose together with the corresponding pieces of the high-temperature insulation. Then the nose and the related attachment components were assembled. These are the metallic brackets plus fasteners that are connected to the hat profiles in the nose.

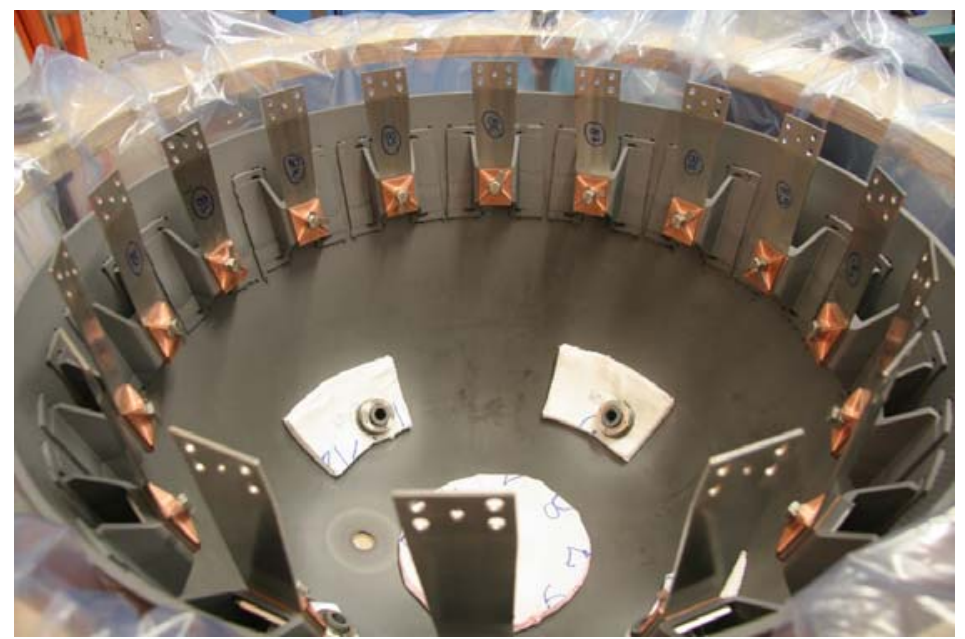

Figure 18: Nose with assembled attachment brackets plus PL1 sensor heads.

The nose with attached bracketry was then fitted on the cold structure colander. On a 3-D coordinate measurement machine the fit was controlled and adjustments to the attachment components were made as necessary. When the correct position was achieved, the brackets were fixed and torqued and their final positions. Then the nose and colander were de-mated.

The next step was to outfit the nose with the insulation packages. Most of the insulation packages had been prepared before. A few smaller pieces had to be adapted to the conditions and were produced during this phase and also the PL10 window assembly was installed. 


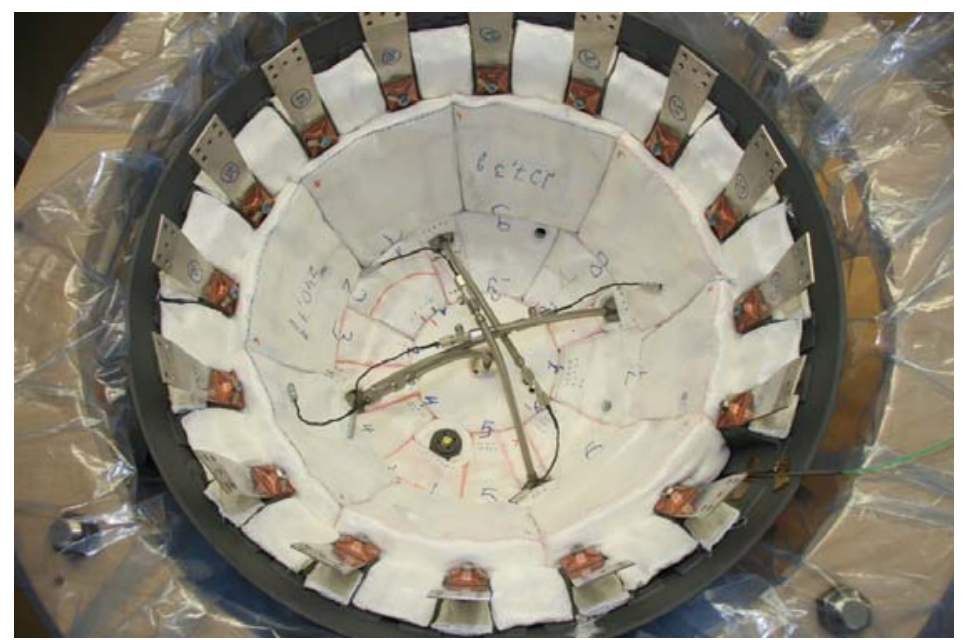

Figure 19: Nose equipped with insulation, PL1 pressure lines and PL10 window

Then the colander was put in place again and as the last step of the insulation package production, the holes required for the PL2 optical access to the nose inner surface were introduced using the colander as the template for the hole positions. The colander was then fixed in its final position. In the last phase of the assembly the transducers of PL1 were installed inside of the colander and the routing of the pressure lines was done to connect the sensor heads in the nose with the transducer housings. The PL2 and PL10 sensor heads on the inside of the colander were put in place and their fibre optic cables were routed inside of the colander.

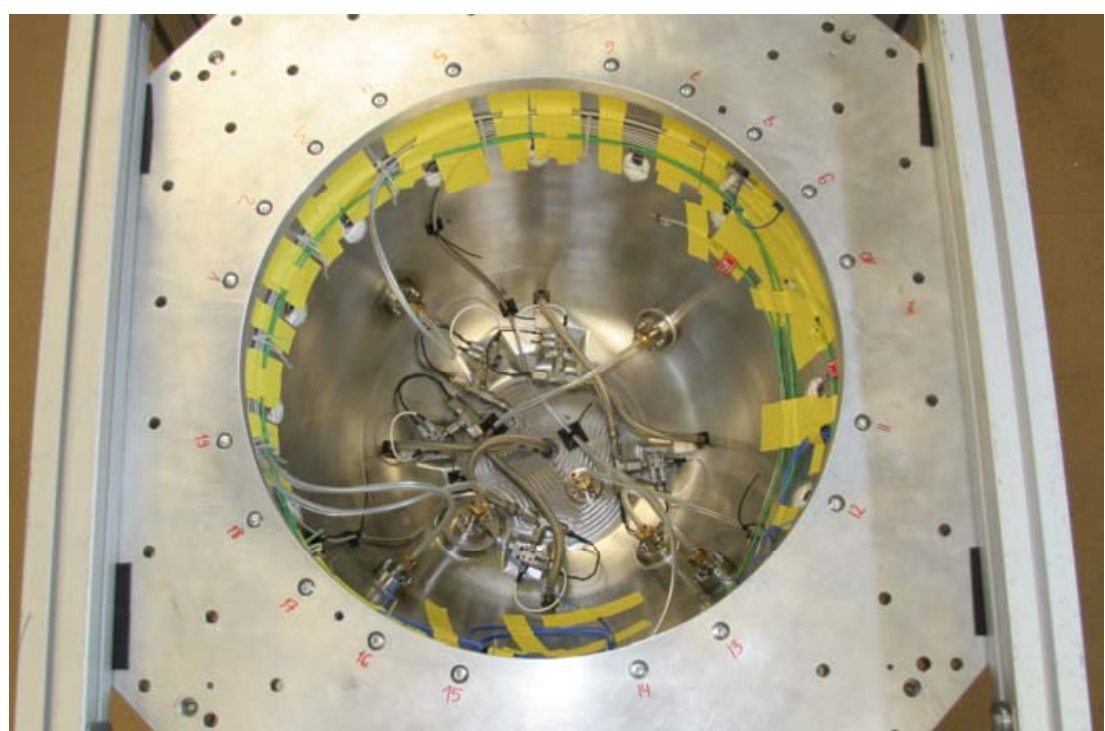

Figure 20: Fully assembled NAP flight model seen from colander side.

\section{NOSE ASSEMBLY TESTS}

Two nose components were used as test articles. One was used to perform a pressure test to demonstrate that the ceramic nose is able to carry the re-entry pressure loads. Another one was used as the qualification model (QM) and was fully assembled with cold structure, insulation and payloads to represent the later flight model (FM). Finally the acceptance tests of the assembled flight model were carried out. The full scale mechanical tests of the QM and the FM were done at the ETS facilities on the ESTEC premises in Noordwijk, Netherlands. 
Shock tests with the QM were done tests at TÜV in Turin, Italy

In addition tests were done to verify the mechanical attachment of the nose to the cold structure on component level and a lot of tests were done to qualify the embedded payloads in the re-entry environment.

Fig. 21 and Fig.22 show the required levels for the mechanical vibration tests in the different axes of the assembly. A reduced level is required for the acceptance tests of the flight model.

\begin{tabular}{|c|c|c|c|}
\hline \multicolumn{2}{|c|}{ NOSE ASSY IF X-AXIS (OOP) } & \multicolumn{2}{|c|}{ Random Vibr. Environment } \\
\hline FREQ(Hz) & $\begin{array}{c}\text { FLIGHT } \\
\text { ASD }(\mathrm{g} 2 / \mathrm{Hz})\end{array}$ & $\begin{array}{c}\text { QUAL } \\
\text { ASD }(\mathrm{q} 2 / \mathrm{Hz})\end{array}$ & Slope (dB/Oct) \\
\hline 20 & 0.001 & 0.002 & \\
\hline 40 & 0.012 & 0.024 & 10.79 \\
\hline 65 & 0.012 & 0.024 & \\
\hline 100 & 0.35 & 0.7 & 23.57 \\
\hline 230 & 0.35 & 0.7 & \\
\hline 350 & 0.007 & $\overline{0.014}$ & -28.05 \\
\hline 600 & 0.007 & 0.014 & \\
\hline 1400 & 0.0035 & 0.007 & -2.46 \\
\hline 2000 & 0.001 & 0.002 & -10.57 \\
\hline GRMS & 8.12 & 11.48 & \\
\hline
\end{tabular}

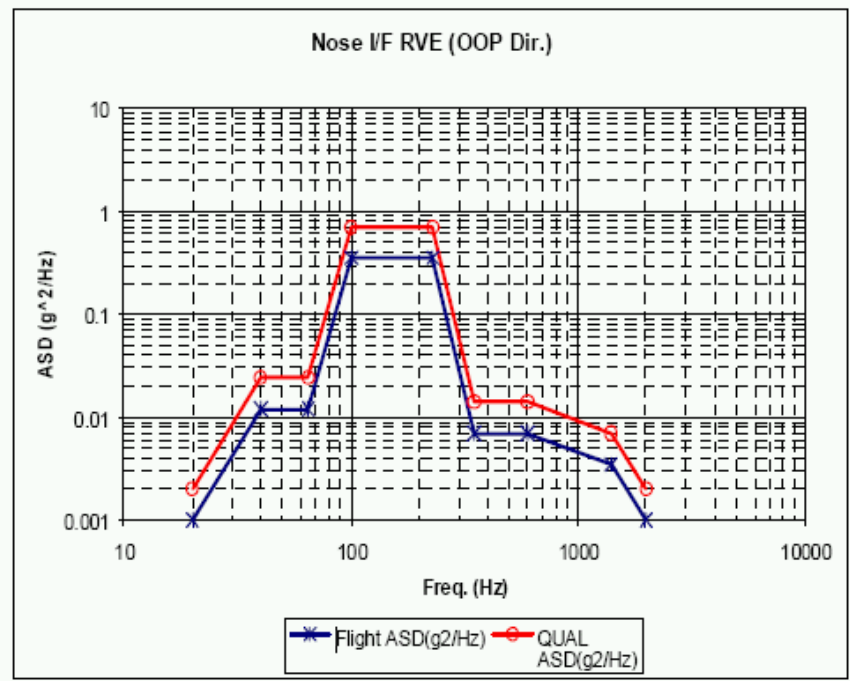

Figure 21: NAP test levels for out-of-plane direction

Before and after each test run a resonance search was carried out with a low level sine sweep test. The load was $0.5 \mathrm{~g}$ between 5 and $2000 \mathrm{~Hz}$ with 2 octaves per minute sweep rate. The test article was equipped with a number of accelerometers. 32 channels were used for the QM, 27 channels were installed on the FM.

\begin{tabular}{|r|r|r|r|}
\hline \multicolumn{2}{|c|}{ NOSE ASSY IF YZ-PLANE (IP) Random Vibr. Environment } \\
\hline \hline \multicolumn{1}{|c|}{ FREQ(Hz) } & $\begin{array}{c}\text { FLGHT } \\
\text { ASD(g2/Hz) }\end{array}$ & $\begin{array}{c}\text { QUAL } \\
\text { ASD(g2/Hz) }\end{array}$ & Slope (dB/Oct) \\
\hline 20 & 0.001 & 0.002 & \\
\hline 40 & 0.08 & 0.16 & 19.03 \\
\hline 50 & 0.08 & 0.16 & -19.20 \\
\hline 60 & 0.025 & 0.05 & \\
\hline 80 & 0.025 & 0.05 & \\
\hline 220 & 0.12 & 0.24 & 4.67 \\
\hline 280 & 0.12 & 0.24 & -19.74 \\
\hline 320 & 0.05 & 0.1 & -24.54 \\
\hline 550 & 0.05 & 0.1 & \\
\hline 700 & 0.007 & 0.014 & \\
\hline 1400 & 0.007 & 0.014 & \\
\hline 2000 & 0.001 & 0.002 & -16.42 \\
\hline GRMS & 6.59 & 9.32 & \\
\hline
\end{tabular}

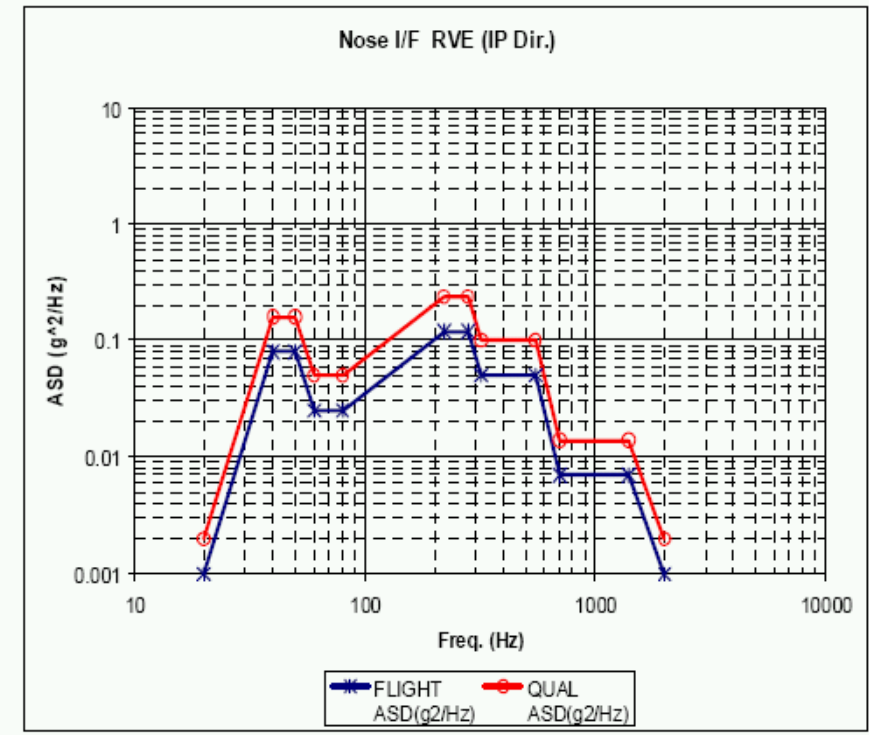

Figure 22: NAP test levels for in-plane direction

Figure 23 shows the QM on the shaker for the in-plane tests, Figure 24 depicts the FM installed for testing in out-of-plane direction. 


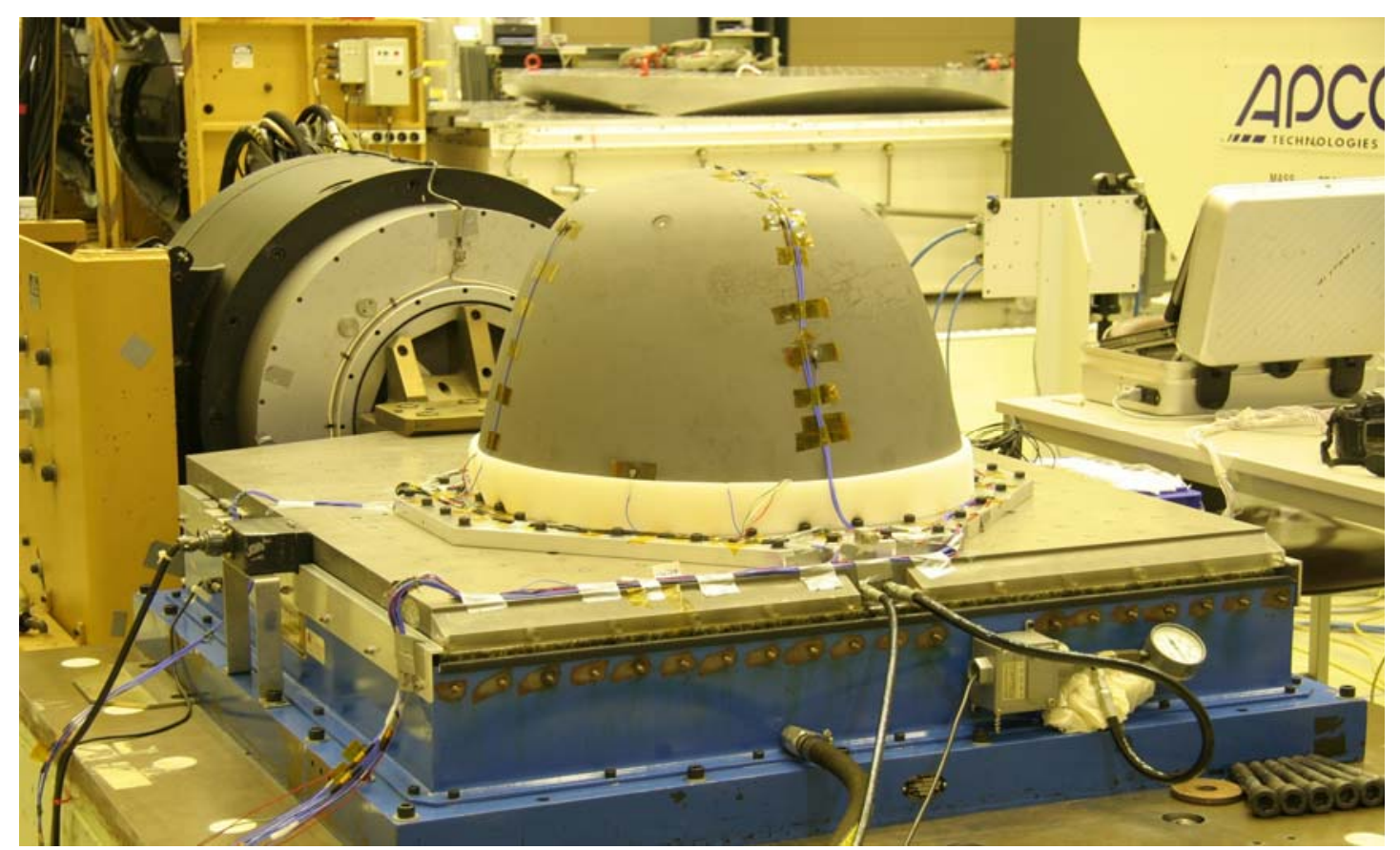

Figure 23: QM in-plane vibration test

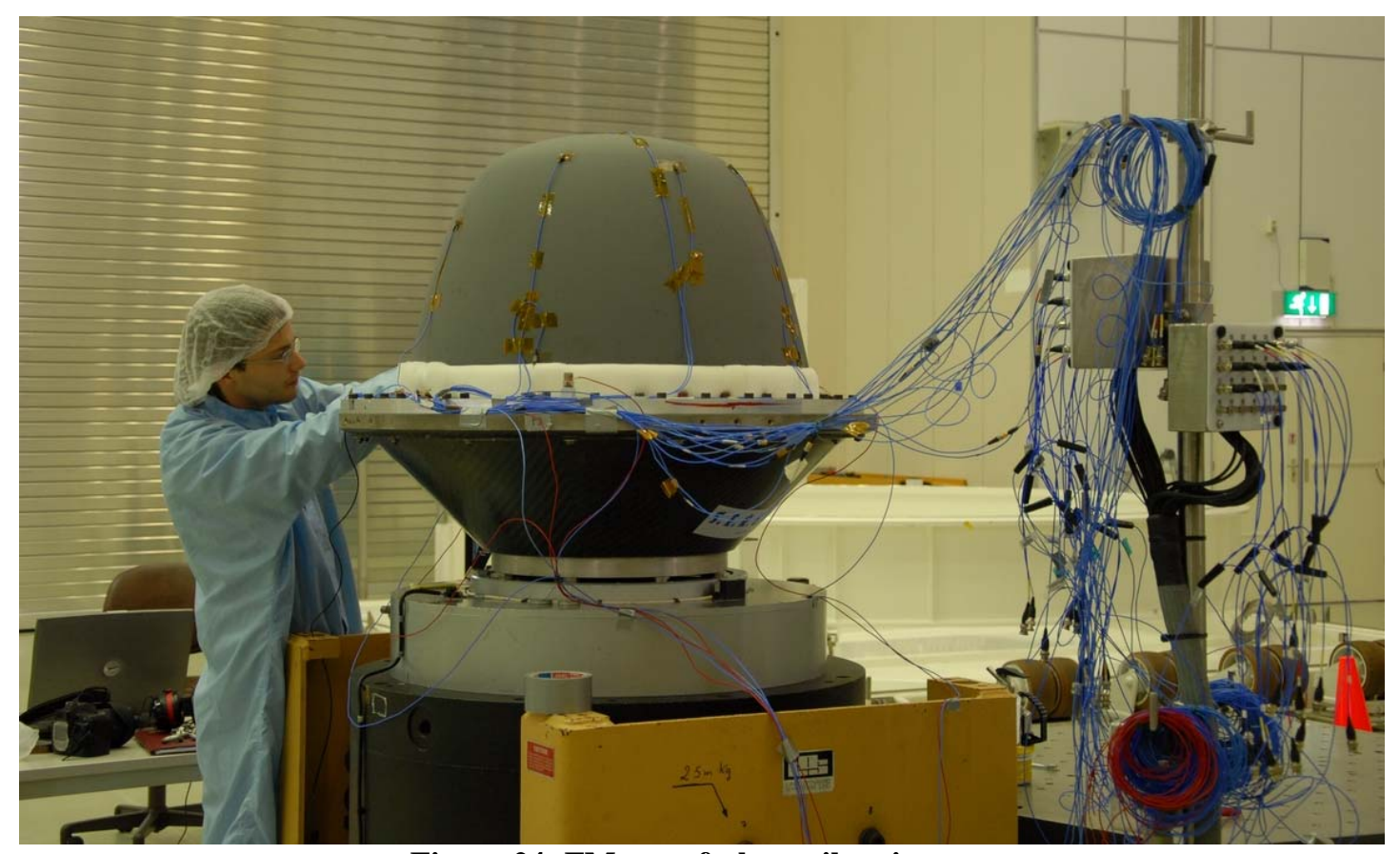

Figure 24: FM out-of-plane vibration test

As an example the results of the in-plane test in Y-axis direction are presented. Figure 25 shows the load levels of the random vibration test and Figure 26 shows the measured values of the resonance search carried out before and after that test. The curves are in good agreement which indicates that the test had no influence on the mechanical properties of the NAP. 


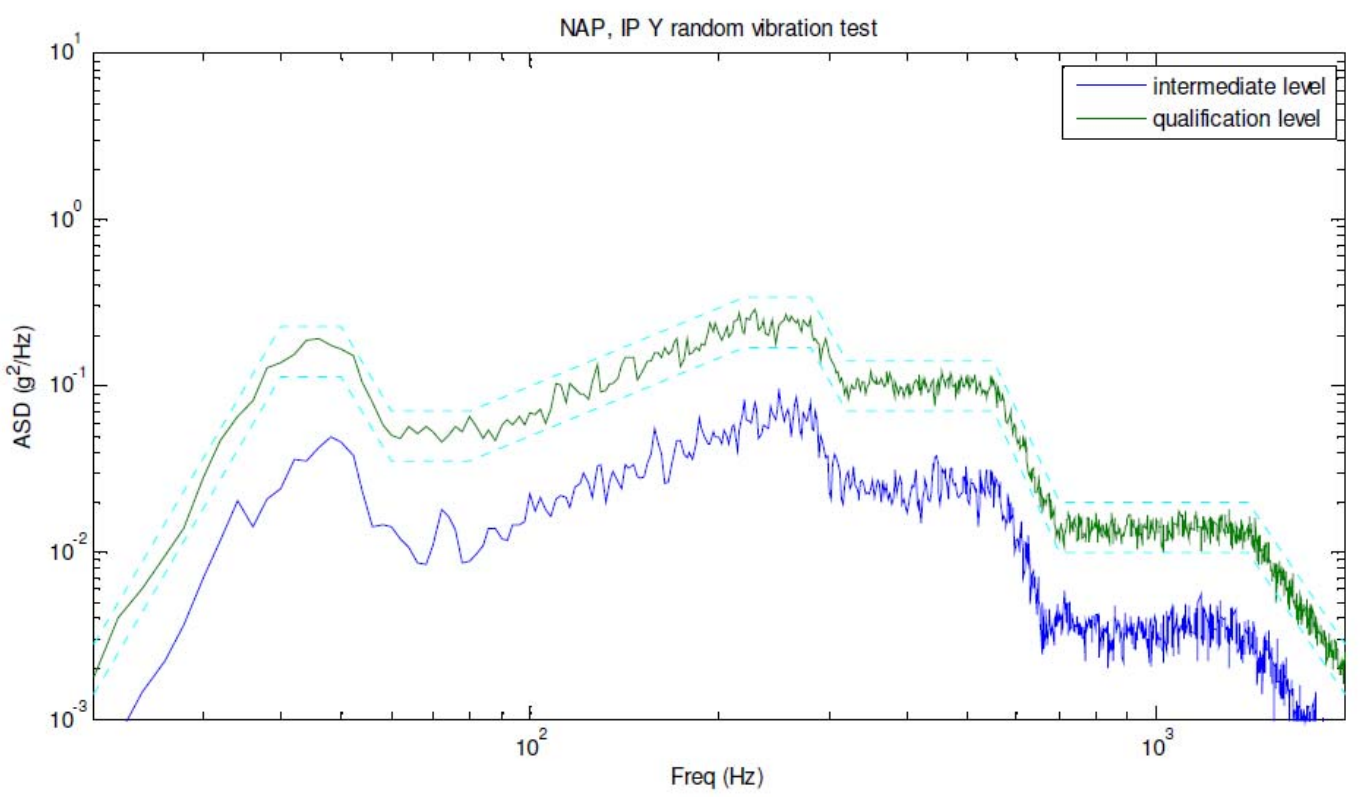

Figure 25: Measured qualification random vibration load levels at the shaker to NAP interface in Y-axis

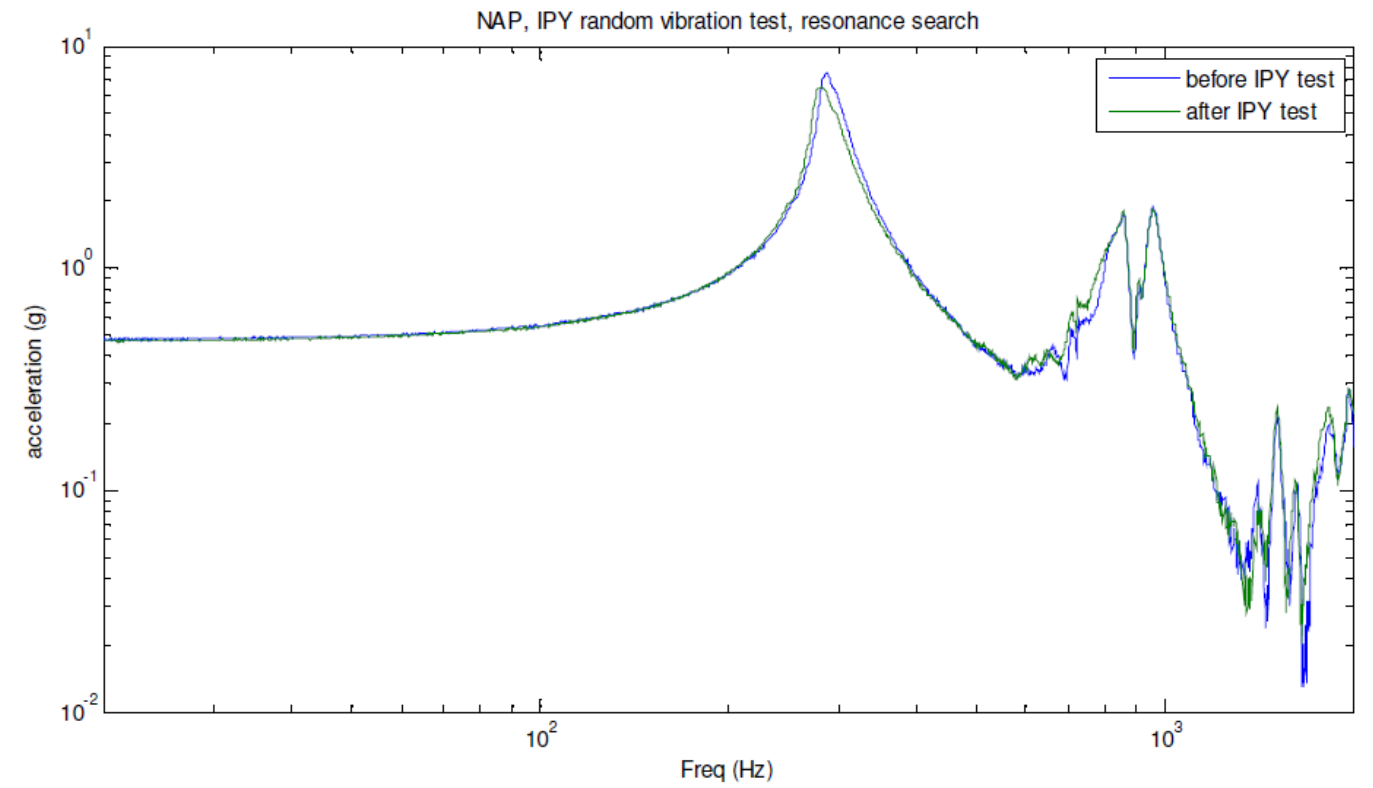

Figure 26: Results of resonance search before and after in-plane Y-axis random vibration qualification test

\section{CONCLUSION}

The development of the CMC instrumented nose system for EXPERT started in DLR-Stuttgart in 2004 with first concepts. The successful completion of the acceptance tests of the flight hardware now reflects a remarkable success that was achieved in the past few years. With a diameter of 716 $\mathrm{mm}$ and a height of $413.5 \mathrm{~mm}$ the CMC nose is the largest and one of the most demanding structures that was built so far at DLR. 
But that story does not only include DLR and the nose but also the payload providers that contributed to the whole package. Also on the payload side, impressing developments have been achieved and exciting results can be expected from the flight data. The payloads will give essential information about the flow conditions but also on the vehicle orientation in the flow. A highlight is certainly the implementation of an optical window for the PL10 spectrometer in the stagnation region of the nose where the surface temperature is over $2000^{\circ} \mathrm{C}$.

The NAP is now ready for integration on the EXPERT vehicle and then to be launched into space.

\section{ACKNOWLEDGEMENTS}

All the work presented here would not have been possible without the support from a lot of people not mentioned in the author list, at DLR but also at HTG and at IRS at Stuttgart University and of course at the different places where contractors did their jobs. To mention just a few, from DLR there are the people from the CMC manufacturing department in Stuttgart who practice their kind of "black" art to produce these structures in their furnaces and in Cologne Mr. Fröbel not only spent his time but also the money on it. Companies like HTG prove that size is not all and IRS is always a center of enthusiasm. There is probably no milling job that Jenewein Modellbau is not willing to tackle and the ceramic machining competence of PMF is above anything. Last but not least, there are good guys in Naples indeed, especially those from CIRA who supported the test campaigns.

\section{REFERENCES}

[1] J. Gavira, EXPERT - A European Aerothermodynamics In-Flight Testbed, Proceedings $6^{\text {th }}$ European Workshop on Thermal Protection Systems and Hot Structures, 1-3 April 2009, Stuttgart, Germany

[2] T. Reimer, T. Laux, Thermal and Mechanical Design of the EXPERT C/C-SiC Nose, Proceedings $5^{\text {th }}$ European Workshop on Thermal Protection Systems and Hot Structures, Noordwijk, The Netherlands, 17-19 May 2006 (ESA SP-631, August 2006)

[3] J. Fatemi, Thermal-Structural Performances of the EXPERT Thermal Protection System, Proceedings $6^{\text {th }}$ European Workshop on Thermal Protection Systems and Hot Structures, Stuttgart, Germany,1-3 April 2009

[4] D.S. Steinberg, Vibration Analysis for Electronic Equipment, $3^{\text {rd }}$ Ed., Wiley \& Sons, New York, 2000

[5] K. Stubicar, T. Reimer, Thermo-Mechanical Design of the EXPERT Nose and Testing of the Load Introductions, Proceedings $6^{\text {th }}$ European Workshop on Thermal Protection Systems and Hot Structures, Stuttgart, Germany,1-3 April 2009

[6] K. Stubicar, T. Reimer, G. Koppenwallner et al., Testing of EXPERT Nose Material and Sensor Heads in the DLR ARCJET Facilities, Proceedings of the $6^{\text {th }}$ Symposium on Aerothermodynamics for Space Vehicles, Versailles, France, 3-6 November 2008

[7] F. Ratti, J. Gavira, A.C. Thirkettle et al., European Experimental Re-Entry Testbed EXPERT: Qualification of Payloads for Flight, Proceedings of the $6^{\text {th }}$ Symposium on Aerothermodynamics for Space Vehicles, Versailles, France, 3-6 November 2008 